\title{
Intraoral kinking of an endotracheal tube during position change in a patient with tracheal deviation
}

\author{
Jihyoung Park, Kwang Ho Lee, Wikwang Wang, \\ Sang Woo Jung, June Ho Choi, Hyun Kyo Lim
}

\begin{abstract}
Introduction: The maintenance of ventilation through the endotracheal tube during surgery is essential, and failure to do so can cause serious consequences. Case Report: We experienced a case of intraoral kinking of the polyvinyl chloride, single-lumen endotracheal tube (ETT) in a patient with severe tracheal deviation caused by pulmonary tuberculosis. During surgery, the operation table was tilted upward and to the left, which caused change in patient's head position and led to intraoral kinking. Conclusion: If there is a severe tracheal deviation expected to cause deformity of the ETT, it is recommended to use a reinforced tube.
\end{abstract}

Keywords: Anesthesia complication, Kinking of endotracheal tube, Temperature, Tracheal deviation

Jihyoung Park ${ }^{1}$, Kwang Ho Lee², Wikwang Wang ${ }^{3}$, Sang Woo Jung ${ }^{3}$, June Ho Choi ${ }^{3}$, Hyun Kyo Lim²

Affiliations: ${ }^{1}$ Clinical fellow, Anesthesiology and Pain Medicine, Wonju Severance Christian Hospital, Wonju, Gangwon-do, Republic of Korea; ${ }^{2}$ Professor, Anesthesiology and Pain Medicine, Yonsei University Wonju College of Medicine, Wonju, Gangwon-do, Republic of Korea; ${ }^{3}$ Resident, Anesthesiology and Pain Medicine, Wonju Severance Christian Hospital, Wonju, Gangwon-do, Republic of Korea.

Corresponding Author: Hyun Kyo Lim, 20, Ilsan-ro, Wonju, Gangwon-do, Republic of Korea, 26426; Email: hyunkyolim@yonsei.ac.kr

Received: 22 September 2017

Accepted: 03 November 2017

Published: 02 February 2018

\section{How to cite this article}

Park J, Lee KH, Wang W, Jung SW, Choi JH, Lim HK. Intraoral kinking of an endotracheal tube during position change in a patient with tracheal deviation. Case Rep Int 2018;7:100043CRINTJP2018.

Article ID: 100043CRINTJP2018

$$
* * * * * * * * *
$$

doi: 10.5348/crint-2018-43-CR

\section{INTRODUCTION}

Securing and maintaining a passage from anesthesia machine to a patient's respiratory tract is a basic element for the safety of the patient. Ventilatory failure caused by airway obstruction during surgery may result in serious complications such as brain damage, and must be detected and resolved early. Airway obstruction can be caused by factors such as closure of the breathing circuit, existence of a foreign body in the tube, or kinking of the tube [1]. Kinking of the endotracheal tube can be caused by improper positioning of the patient during surgery [2-4] and thermal softening of tube $[5,6]$.

We report a case of a patient with a severe tracheal deviation who underwent insertion of a polyvinyl chloride (PVC), single-lumen endotracheal tube (ETT) and experienced intraoral kinking after a change in position.

\section{CASE REPORT}

A 76-year-old female with a height $150 \mathrm{~cm}$ and a weight $41 \mathrm{~kg}$ was scheduled to undergo laparoscopic cholecystectomy under the diagnosis of chronic cholecystitis. She had been diagnosed with pulmonary 
tuberculosis 11 years prior. Preoperative laboratory results showed no specific findings, the chest X-ray revealed a destruction of the right lung with tracheal deviation (Figure 1), and pulmonary function test (PFT) result showed a small airway obstructive lung defect.

General anesthesia was induced with injection of propofol intravenously and infusion of remifentanil. Rocuronium was used as a muscle relaxant, followed by intubation with a conventional PVC, single-lumen ETT (Hi-Lo oral/nasal tracheal tube cuffed, COVIDIEN ${ }^{\mathrm{TM}}$ Mallinckrodt $^{\mathrm{TM}}$, Ireland, ID $6.5 \mathrm{~mm}$ ). Although there was slight resistance during intubation, auscultation confirmed clear lung sounds in both lungs, and the ETT was fixed at a depth of $22 \mathrm{~cm}$ from the incisor. Anesthesia was maintained with $4-5 \%$ desflurane and remifentanil infusion of $0.08-0.125 \mu \mathrm{g} / \mathrm{kg} / \mathrm{min}$. The ventilator settings were as follows: tidal volume $260 \mathrm{ml}$, respiratory rate 12 per min, positive end-expiratory pressure $5 \mathrm{cmH}_{2} \mathrm{O}$, and fraction of inspired oxygen concentration 0.5. Esophageal temperature was $36.0^{\circ} \mathrm{C}$.

Eight minutes into surgery, the position of the patient was changed from supine to reverse-Trendelenburg with a slight tilt to the left. Suddenly, monitoring alarm for airway pressure was activated with an increase in peak airway pressure from $19 \mathrm{cmH}_{2} \mathrm{O}$ to $35 \mathrm{cmH}_{2} \mathrm{O}$ and a decrease in tidal volume to $50 \mathrm{ml}$. End-tidal $\mathrm{CO}_{2}$ monitoring first showed obstructive pattern followed by a sudden fall in the value to $10 \mathrm{mmHg}$, and then was not detected at all. The ventilator setting was converted to manual ventilation, but tidal volume could not be attained. There were no signs of tube blockage outside of the mouth or damage to the circuit. Breathing circuit and extraoral portion of the tube were checked with no signs of obstruction or kinking.

The patient's head was noted to be slightly flexed, so we extended it, which improved tidal volume to 200 $\mathrm{ml}$ with a respiratory rate of 20 per minute and allowed measurement of end-tidal $\mathrm{CO}_{2}$ partial pressure at 60 $\mathrm{mmHg}$. One minute later, however, the airway pressure increased again, and sufficient tidal volume was not maintained. Manual ventilation was attempted again; there was no improvement and obstruction was observed. We attempted to insert a suction catheter into the tube, but it would not pass beyond the tube midline.

Using a laryngoscope, we examined the oral cavity and found that the ETT was bent at the anterior part of the epiglottis (Figure 2). A request was made to stop the surgery, and re-intubation using a reinforced ETT (LoContour oral/nasal tracheal tube cuffed, COVIDIAN ${ }^{\mathrm{TM}}$ Mallinckrodt $^{\mathrm{TM}}$, Ireland, ID $6.5 \mathrm{~mm}$ ) was performed. After tube exchange, surgery was resumed, and there were no other unusual events through the end of the operation.

\section{DISCUSSION}

Sezkely et al. reported that, in an analysis of endotracheal tube (ETT) problems, endobronchial

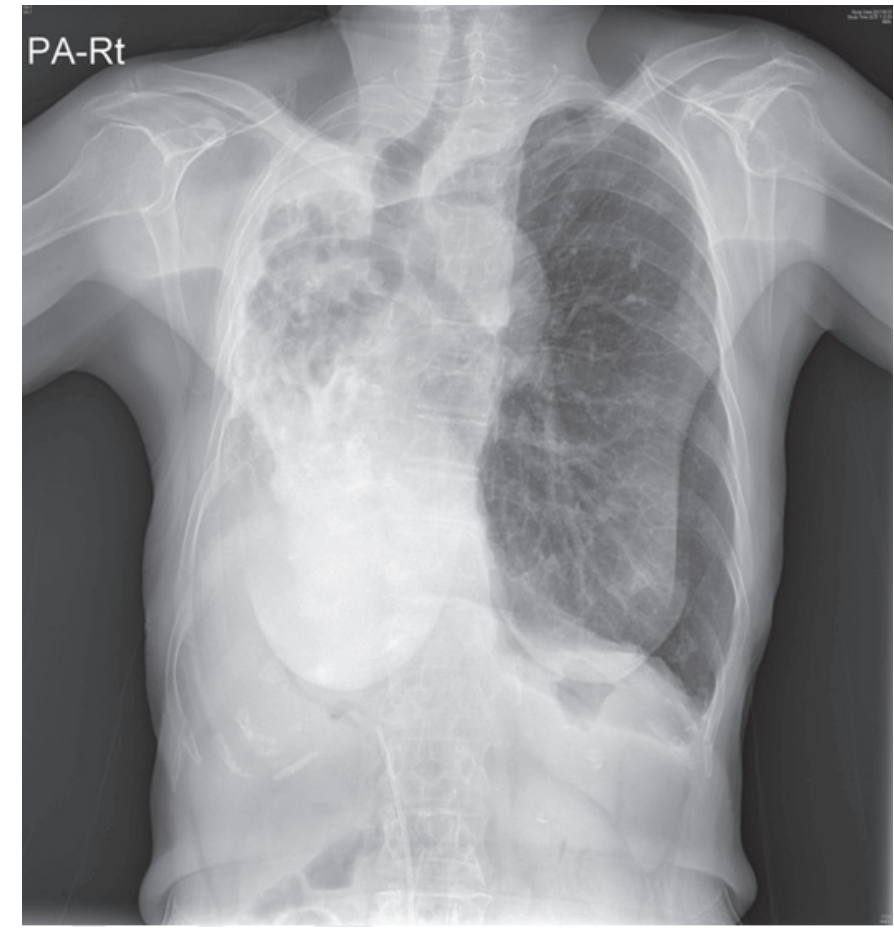

Figure 1: Chest posteroanterior X-ray showing a destruction of the right lung with severe tracheal deviation.
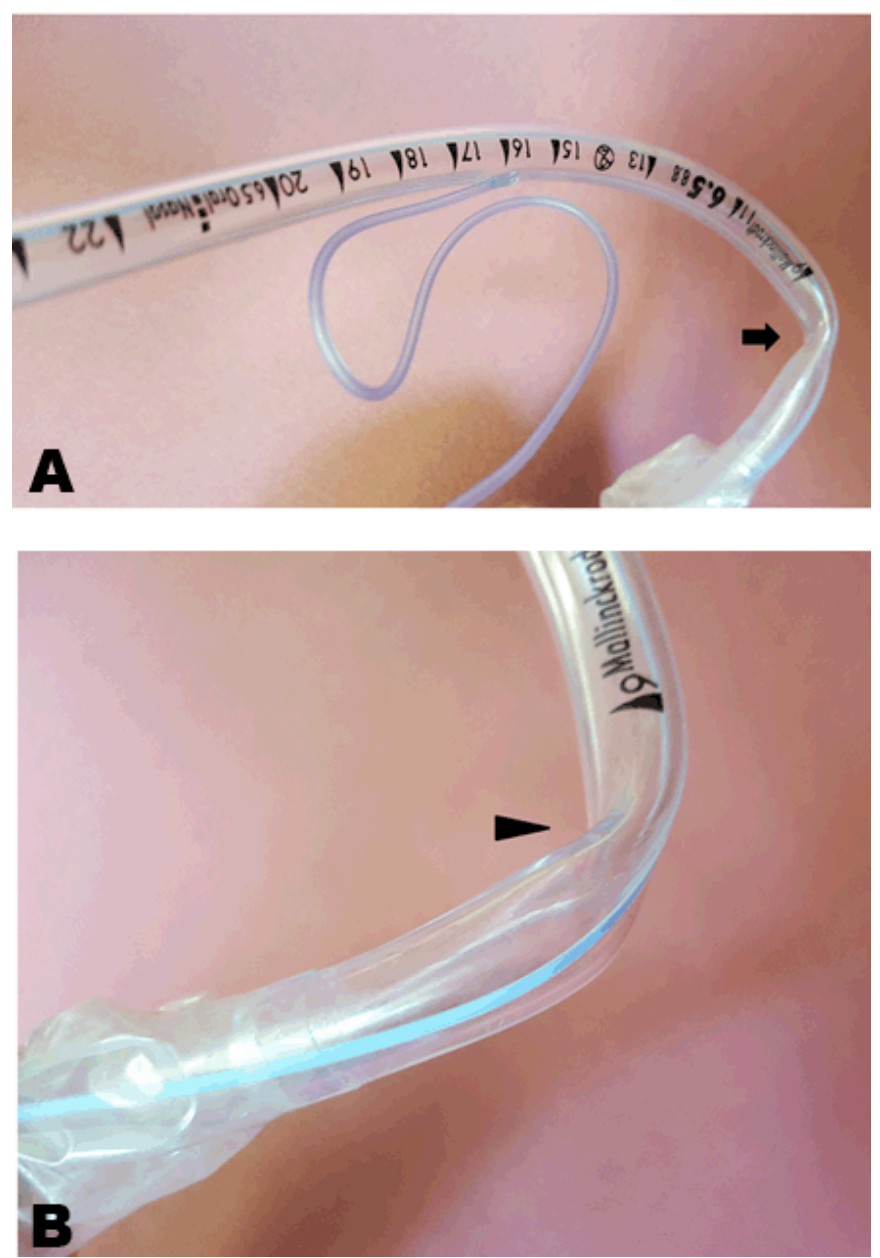

Figure 2: Endotracheal tube (ETT) removed from the patient: (A) Kinked ETT (arrow), and (B) Kinked in an unusual direction (arrow head). 
intubation was the most common, followed by obstruction and kinking, esophageal intubation, disconnection, leakage, and cuff hernia [1]. Kinking of the ETT occurs mainly outside of the mouth, with occurrence in the intraoral portion rarely reported $[1,5,7,8]$.

Partial or complete kinking of the tube can occur depending on the vector direction of the force applied to the fixed tube in the intraoral region, which is mostly affected by patient positioning [2-4, 9]. Prone positioning during posterior fossa surgery with neck flexion may cause tube kinking [2], particularly when the atlanto-axial joint is maximally flexed [4]. It has been reported that even in supine position, intraoral tube kinking occurred thirty minutes after intubation, causing ventilation impossible. Although tube patency was maintained, increase in the tube temperature caused softening of the tube eventually causing kinking [6]. Occurrence of kinking might increase with vector of forces according to position and thermal softening of the tube.

In care of patients, it is important to anticipate complications and use preventive measures to prevent the risk of kinking. There are reasons why we used single lumen tube instead of reinforced tube. After evaluating patient's chest X-ray for tracheal deviation, it seemed that use of single lumen tube would not be a problem. Also, our nation provides all citizens with NHI (National Health Insurance). NHI controls all aspects of medical services, including medical supplies. According to NHI guideline, reinforced tube is not indicated in our case, limiting its use.

In this case, we believe that three factors were involved in the kinking of the ETT. First, the patient's right lung was destroyed by pulmonary tuberculosis, and the airway was severely deviated to the right. It is possible that an abnormal force was applied to the right side of the PVC tube due to this deviation. Secondly, the patient was small in stature, and the pillow might have been relatively high, causing severe flexion. Also, at the beginning of the surgery, the operation table was tilted upward, which might have applied further force that led to kinking of the tube. Finally, if the oral temperature rises above $36^{\circ} \mathrm{C}$, the PVC of the tube can soften and increase the risk of bending [6]. In this case, the body temperature during the operation was $36^{\circ} \mathrm{C}$.

\section{CONCLUSION}

Factors such as anatomical variation e.g., tracheal deviation, position change during surgery, and thermal softening of the tube may act singly or in combination to cause endotracheal tube kinking. If the patient is in high risk, we strongly recommend using reinforced tube.

\section{REFERENCES}

1. Szekely SM, Webb RK, Williamson JA, Russell WJ. The Australian incident monitoring study. Problems related to the endotracheal tube: An analysis of 2000 incident reports. Anaesth Intensive Care 1993 Oct;21(5):611-6.

2. Bharti N, Bala I. Kinking of endotracheal tube during posterior fossa surgery. Indian $\mathrm{J}$ Anaesth 2010 Mar;54(2):172-3.

3. Bhagat H, Kumar P, Thimmarayan G. Predisposition of snugly fitting endotracheal tube to intraoral kinking during paediatric neurosurgery in the prone position. Anaesth Intensive Care 2010 Nov;38(6):1141-2.

4. Campoy L, Hughes JM, McAllister H, Bellenger CR. Kinking of endotracheal tubes during maxima flexion of the atlanto-occipital joint in dogs. J Small Anim Pract 2003 Jan;44(1):3-7.

5. Leissner KB, Ortega R, Bodzin AS, Sekhar P, Stanley GD. Kinking of an endotracheal tube within the trachea: A rare cause of endotracheal tube obstruction. J Clin Anesth 2007 Feb;19(1):75-6.

6. Hübler M, Petrasch F. Intraoperative kinking of polyvinyl endotracheal tubes. Anesth Analg 2006 Dec;103(6):1601-2.

7. Aqil M, Al-Saeed A. A simple solution to unexpected kinking of endotracheal tube. Saudi J Anaesth 2013 Jul;7(3):344-6.

8. Hariharan U, Garg R, Sood R, Goel S. Intraoperative kinking of the intraoral portion of an endotracheal tube. J Anaesthesiol Clin Pharmacol 2011 Apr;27(2):290-1.

9. Ohata H, Iida $\mathrm{Y}$, Kito $\mathrm{K}$, et al. Kinking of the endotracheal tube in a prone patient associated with the inadequate withdrawal maneuver of the PentaxAWS Airway Scope. [Article in Japanese]. Masui 2013 Jun;62(6):674-7.

$$
* * * * * * * * *
$$

\section{Author Contributions}

Jihyoung Park - Substantial contributions to conception and design, Acquisition of data, Analysis and interpretation of data, Drafting the article, Revising it critically for important intellectual content, Final approval of the version to be published

Kwang Ho Lee - Substantial contributions to conception and design, Revising it critically for important intellectual content, Final approval of the version to be published Wikwang Wang - Substantial contributions to conception and design, Acquisition of data, Analysis and interpretation of data, Drafting the article, Final approval of the version to be published

Sang Woo Jung - Analysis and interpretation of data, Drafting the article, Revising it critically for important intellectual content, Final approval of the version to be published

June Ho Choi - Analysis and interpretation of data, Revising it critically for important intellectual content, Final approval of the version to be published

Hyun Kyo Lim - Substantial contributions to conception and design, Acquisition of data, Analysis and interpretation of data, Drafting the article, Revising it critically for important intellectual content, Final approval of the version to be published 


\section{Guarantor of Submission}

The corresponding author is the guarantor of submission.

\section{Source of Support}

None

\section{Conflict of Interest}

Authors declare no conflict of interest.

\section{Copyright}

(C) 2018 Jihyoung Park et al. This article is distributed under the terms of Creative Commons Attribution License which permits unrestricted use, distribution and reproduction in any medium provided the original author(s) and original publisher are properly credited. Please see the copyright policy on the journal website for more information.
Access full text article on other devices

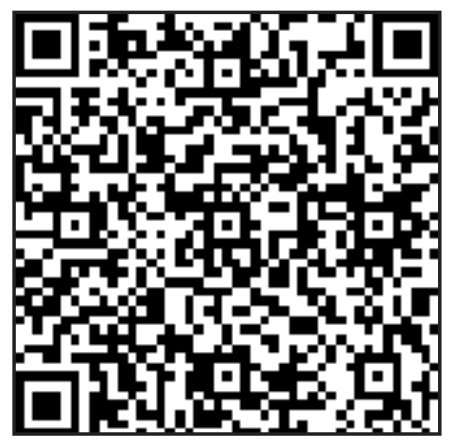

Access PDF of article on other devices

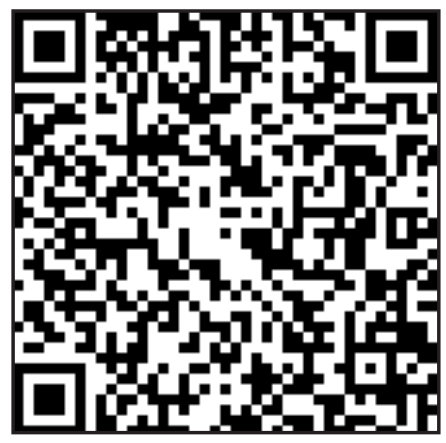

